\title{
Targeting dendritic cells as a good alternative to combat Leishmania spp.
}

\section{Rafael de Freitas e Silva ${ }^{1,2 *}$, Maria Carolina Accioly Brelaz de Castro ${ }^{2}$, Antônio Mauro Rezende ${ }^{3}$ and Valéria Rêgo Alves Pereira ${ }^{2}$}

${ }^{1}$ Department of Natural Sciences, University of Pernambuco, Garanhuns, Brazil

${ }^{2}$ Department of Immunology, Aggeu Magalhães Research Center, Oswaldo Cruz Foundation, Recife, Brazil

${ }^{3}$ Department of Microbiology, Aggeu Magalhães Research Center, Oswaldo Cruz Foundation, Recife, Brazil

*Correspondence: rafael.silva@upe.br

Edited by:

Lee Mark Wetzler, Boston University School of Medicine, USA

Reviewed by:

Paul Cos, Antwerp University, Belgium

Keywords: dendritic cells, vaccine, neglected diseases, leishmaniasis

\section{LEISHMANIASIS: GLOBAL BURDEN, CLINICAL FORMS, AND CURRENT STRATEGIES OF CONTROL}

Leishmaniasis is an important group of neglected diseases caused by more than 20 spp. of protozoan from the genus Leishmania. It is transmitted by sandfly bite (1), and impacts populations by inducing disfiguration, loss of productivity, and a burden estimated at 2,357.000 disabilityadjusted life years (DALY) (2). Ninetyeight countries have reported cases of leishmaniasis, and over 350 million people are living at risk, with $0.2-0.4$ and $0.7-$ 1.2 million cases of VL and CL annually, respectively (3). Three main clinical forms are known: visceral (VL, more lethal, e.g., $L$. donovani and $L$. infantum), cutaneous (CL, more common, e.g., L. major), and mucocutaneous (MCL). Strategies to limit these diseases are controlling the vectors and chemotherapy of affected individuals, but these approaches have a high cost and led to resistant parasites and vectors (4). Thus, there is an urgent need of vaccines and more effective therapies for leishmaniasis, otherwise the number of cases and resistant strains will probably continue to rise. Since they have a key capacity to initiate and maintain an immune response, dendritic cells (DCs) have been seen as an important target for the control of different diseases, such as leishmaniasis. Thus, in this article we present the principal strategies to efficiently induce activation of DCs in the context of leishmaniasis.

\section{DENDRITIC CELLS AS THE MAIN TARGET OF VACCINES AGAINST LEISHMANIA}

The major task for a vaccine is to correctly induce the immune system to develop a protective response against one specific pathogen. In the case of leishmaniasis, this protection comes from Th1 CD4 ${ }^{+} \mathrm{T}$ cells producing IFN- $\gamma$, TNF, and IL-12, which have been associated with disease control, macrophage activation, and elimination of parasites (5). However, to initiate this response, antigen presenting cells (APCs), present in different tissues of the body, must be activated to induce a proper response to eliminate or control the parasite. DCs are highly specialized APCs of the immune system capable of priming naïve $\mathrm{T}$ cells, and mounting a T-cell response upon pathogen entry in the body. Distinct subsets of DCs are associated with lineages and receptor expression patterns (6), and they develop from hematopoietic stem cells stimulated with fms-like tyrosine kinase 3 ligand (Flt3L) or with granulocyte/macrophage colony-stimulating factor (GM-CSF) (7). The majority of DCs develop from myeloid precursors, whereas plasmacytoid DC (pDC) develops from lymphoid precursors and shares many features with B cells (8). To aid in their function, DCs express different toll-like receptors (TLR), which bind to common molecules associated with pathogens, and have been target for the development of new vaccine adjuvants. DCs express a large variety of receptors involved with uptake of molecules and pathogens, such as DC-SIGN (CD209) and DEC205 (CD205) (9). Immature DCs have a high endocytic capacity, which leads to pathogen or pathogen's antigens degradation, processing, and finally loading of major histocompatibility complex (MHC) molecules. Later, mature DCs lose their high capacity of endocytosis, and change efforts to up-regulate the expression of several receptors for cytokines, MHC, adhesion, and co-stimulatory molecules, such as CD80, CD86, and CD40. It is estimated that each mature DC expresses around $10^{6}-10^{7}$ MHC Class II and $10^{5}$ MHC Class I molecules, and "fix" a repertoire of peptides bounded onto MHC Class II to present to T cells (10). Eventually, DCs acquire capacity to activate a specific T-cell response against the pathogen that induced its activation (11). The last years were marked by an increase in the knowledge on the role and function of DCs in the immune system, and thus, the emergence of potential applications based on its manipulation. Starting on the field of cancer, which finally led to the US FDA approval of a DC-based vaccine against prostate cancer (Sipuleucel-T, Provenge ${ }^{\circledR}$ ) (12), applications were quickly transferred to the field of infectious diseases with very encouraging clinical results against HIV (13). Although prospective results for infectious diseases were achieved, there is no DC vaccine or therapy for any infectious diseases that are currently available or in the pipeline (14, 15). Most of the results were gathered by 
ex vivo manipulation of DCs, and in vitro assays by loading it with desired antigens.

\section{EX VIVO ASSAYS WITH DCs}

Different researches have shown interesting results with murine models vaccinated with DCs ex vivo loaded with leishmania lysate antigen $(14,16)$. These results were encouraging since they showed that animals presented low levels of parasite burden and high levels of protective cytokines from the Th1 profile after vaccination. DCs engineered to overexpress IL-12 were successfully used for both vaccination and immunotherapy of murine models with infections already established (17). Interestingly, it was also reported that different subsets of DCs may induce different responses upon activation. Vaccination of $\mathrm{BALB} / \mathrm{c}$ mice with pDCs pulsed with $L$. major complete antigen showed that they were protected against subsequent infection (18). In parallel, the use of DCs pulsed with $L$. donovani-soluble antigen combined with chemotherapy with pentavalent antimonials was able to eradicate parasites from infected mice (19). Curiously, regarding viability of DCs present in the vaccine, Schnitzer et al. (20) have reported that fragments of DCs or exosomes derived from DCs that had been previously exposed to parasite lysate of $L$. major, conferred protection in susceptible mice. Although modulation of DCs activity is highly dependent on the specie of Leishmania causing the infection, some of these studies were performed using $L$. major that is responsible for cases of CL. Thereby, there is an outstanding importance of studies dedicated to evaluate the action of molecular defined antigens of Leishmania spp. in the activity of DCs as a target for vaccines. Furthermore, many antigens from the Leishmania spp. proteome have unknown function and could be keymolecules to induce protective immunity. The importance of using defined antigens is so expressive that DCs pulsed with peptide (154-169aa) from gp63 induced a Th1 protection in $\mathrm{BALB} / \mathrm{c}$ mice infected with L. major, while stimulation with a second peptide (467-482aa) resulted in a Th2 shift and disease exacerbation (21). In this sense, computational immunology has been constantly increasing its value, and now diverse in silico approaches are available for identification of potential epitopes and antigens for vaccines, since experimental methods are difficult and time-consuming (22). In addition, the DNA sequencing techniques are getting cheaper, therefore, many parasite genome strains can be sequenced and their predicted proteomes can be assessed regarding their variability, an important feature for antigen candidates for vaccine development. Thus, sequence- and structure-based methods investigating the binding affinity of peptides to the MHC molecules Class I and II, and other parameters such as sequence diversity may aid in the search of new antigens (23). Taking advantages of these methods, Agallou et al. (24) have recently reported the construction of a multi-epitope peptide vaccine against leishmaniasis by analyzing four known proteins from $L$. infantum. In this last study, some of the proteins (histone $\mathrm{H} 1$ and KMP-11) have been previously tested in DCs vaccines against $L$. infantum (25, 26). Different studies for vaccines against Leishmania spp. have used defined molecules for classical immunization, without considering aspects of DCs activation, and maintenance of a Th1 response by memory cells. DCs have been implicated with the induction of a Th1 immune response through the production of IL-12, as seen in C57BL/6 and $\mathrm{C} 3 \mathrm{H}$ resistant mice strains. On the other hand, BALB/c susceptible mice are more prone to produce a Th2 immune response with the presence of IL4, IL-5, and IL-13; IL-4 ${ }^{-1-}$ BALB/c mice were capable to partially control the infection with some strains of L. major (27). It has been shown that IL-4 during the early phase of DC activation induces a potent Th1 response induced by IL-12 (28); and in the context of vaccination with DCs, it was reported that IL-4 might be an important adjuvant, since IL-4R $\alpha$ signaling is key to promote a Th1 immune response (14). Studies have enrolled IL-10 with disease progression by means of suppression of the anti-leishmanial immune response in humans and mice (29-31). Recently, Schwarz et al. (16) have shown that $\mathrm{T}$ cell are the main source of IL-10 in early infection, however, BALB/c mice vaccinated with fragmented DCs that had been pulsed with $L$. major lysate and $\mathrm{CpG}$ oligodeoxynucleotides (CpG-ODN) were able to suppress IL-10 favoring the control of infection. One of the main concerns in the vaccine development is the use of adjuvants, in this regard, DC approaches in leishmaniasis studies have used, mainly, CpG-ODN, which is a TLR9 ligand (32). The effect of CpG-ODN is to induce DC activation and maturation, enhancing humoral responses, with Th1 indicator IgG2a antibodies, and activity of cytotoxic T lymphocytes (CTL) $(33,34)$. It has been shown that CpG-ODN induce the production of CXCL10, a chemokine with antileishmanial properties, regulation of parasitic load, and $\mathrm{CD} 4{ }^{+} \mathrm{CD} 25^{+}$regulatory $\mathrm{T}$ (Treg) cells in mice infected with $L$. donovani $(35,36)$. Some issues may concern this approach of ex vivo activation, such as the type of antigen that is used, the method itself, which is time-consuming and labor, and also the high risk of infection.

\section{OVERALL ADVANTAGES OF IN VIVO ACTIVATION OF DCS}

Toward a more rational and feasible DCbased vaccine against different pathogens, groups of research have endeavored to in vivo manipulate $\mathrm{DCs}$, and thus, trying to understand the ways of induction a specific $\mathrm{T}$ cell response. In a very interesting work, Bonifaz et al. (37) have demonstrated that it is possible to manipulate DCs in vivo by directing antigen-conjugated antibodies against uptake receptors (DEC205). Other works followed the same strategy and achieved promising results for different pathogens, such as HIV, and also induction of immunity in distinct sites that are challenges for classical route immunization, such as mucosal sites $(38,39)$. For L. major, it was shown that in vivo targeting of DEC205 receptor of DCs with different antigen (LACK, LeIF, LmSTI1a)conjugated antibodies can elicit a protective immune response with INF- $\gamma$ and TNF- $\alpha$ in different mice strains (40). Therefore, based on these results collected during the last years, other uptake receptors could be a target to proper induce DCs maturation and activation. Nevertheless, as well as for other approaches, for a vaccine against Leishmania is not different, as there is a big gap in translating the research from murine models to humans due to environmental and genetic differences (41). Since murine models are difficult and do not always reproduce Leishmania infection, it might be interesting to test some of these approaches with cells from individuals affected or living in endemic regions, 
like recently described for other types of vaccine (42). Another ongoing challenge to be considered is the number of DCs present in vivo. DCs in vivo are rarer than other leukocyte populations. To overcome this issue, it has been shown that using Flt3L in vivo through gene transfection, one can enhance the number of DCs in vivo (43). In this context, it is worth mentioning the importance of works designed for VL, due to its high mortality level. However, in terms of number of cases and morbidity, CL and MCL are much more expressive than VL, especially in developing nations, such as Brazil.

\section{CONCLUSION AND PERSPECTIVES}

The results of DCs-based vaccines against leishmaniasis are very encouraging; demonstrating that either ex vivo or in vivo target of DCs can elicit an effective immune response to combat Leishmania spp. However, a number of biological and methodological challenges should be overcome prior to the development of a DCs-based vaccine. It is possible that moving researches forward to animal, and then, clinical studies will better point out if the target of DCs is safe and effective for an anti-Leishmania spp. vaccine.

\section{REFERENCES}

1. Beaumier CM, Gillespie PM, Hotez PJ, Bottazzi ME. New vaccines for neglected parasitic diseases and dengue. Transl Res Sep (2013) 162(3):144-55. doi:10.1016/j.trsl.2013.03.006

2. Hotez PJ, Ferris MT. The antipoverty vaccines. Vaccine (2006) 24(31-32):5787-99. doi:10.1016/j. vaccine.2006.05.008

3. Alvar J, Vélez ID, Bern C, Herrero M, Desjeux $\mathrm{P}$, Cano J, et al. Leishmaniasis worldwide and global estimates of its incidence. PLoS One (2012) 7(5):e35671. doi:10.1371/journal.pone.0035671

4. Sacks DL. Vaccines against tropical parasitic diseases: a persisting answer to a persisting problem. Nat Immunol (2014) 15(5):403-5. doi:10.1038/ni. 2853

5. Brelaz-de-Castro MC, de Almeida AF, de Oliveira AP, de Assis-Souza M, da Rocha LF, Pereira VR. Cellular immune response evaluation of cutaneous leishmaniasis patients cells stimulated with Leishmania (Viannia) braziliensis antigenic fractions before and after clinical cure. Cell Immunol (2012) 279(2):180-6. doi:10.1016/j.cellimm.2012. 11.006

6. Merad M, Sathe P, Helft J, Miller J, Mortha A. The dendritic cell lineage: ontogeny and function of dendritic cells and their subsets in the steady state and the inflamed setting. Annu Rev Immunol (2013) 31(1):563-604. doi:10.1146/ annurev-immunol-020711-074950
7. Geissmann F, Manz MG, Jung S, Sieweke MH, Merad M, Ley K. Development of monocytes, macrophages, and dendritic cells. Science (2010) 327(5966):656-61. doi:10.1126/science. 1178331

8. Asselin-Paturel C, Boonstra A, Dalod M, Durand I, Yessaad N, Dezutter-Dambuyant C, et al. Mouse type I IFN-producing cells are immature APCs with plasmacytoid morphology. Nat Immunol (2001) 2:1144-50. doi:10.1038/ni736

9. Tel J, Sittig SP, Blom RA, Cruz LJ, Schreibelt G, Figdor CG. Targeting uptake receptors on human plasmacytoid dendritic cells triggers antigen cross presentation and robust type I IFN secretion. J Immunol (2013) 191:5005-12. doi:10.4049/ jimmunol.1300787

10. Inaba K, Turley S, Iyoda T, Yamaide F, Shimoyama $\mathrm{S}$, Reis e Sousa C. The formation of immunogenic major histocompatibility complex class II peptide ligands in lysosomal compartments of dendritic cells is regulated by inflammatory stimuli. J Exp Med (2000) 191(6):927-36. doi:10.1084/jem.191. 6.927

11. Banchereau J, Steinman RM. Dendritic cells and the control of immunity. Nature (1998) 392(6673):245-52. doi:10.1038/32588

12. Kantoff PW, Higano CS, Shore ND, Berger ER, Small EJ, Penson DF, et al. Sipuleucel-T immunotherapy for castration-resistant prostate cancer. N Engl J Med (2010) 363:411-22. doi:10. 1056/NEJMoa1001294

13. García F, Plana M, Climent N, León A, Gatell JM, Gallart T. Dendritic cell based vaccines for HIV infection: the way ahead. Hum Vaccin Immunother (2013) 9:2445-52. doi:10.4161/hv.25876

14. Masic A, Hurdayal R, Nieuwenhuizen NE, Brombacher F, Moll H. Dendritic cell-mediated vaccination relies on interleukin-4 receptor signaling to avoid tissue damage after Leishmania major infection of BALB/c mice. PLoS Negl Trop Dis (2012) 6:e1721. doi:10.1371/journal.pntd.0001721

15. Cohn L, Delamarre L. Dendritic cell-targeted vaccines. Front Immunol (2014) 5:255. doi:10.3389/ fimmu.2014.00255

16. Schwarz T, Remer KA, Nahrendorf W, Masic A, Siewe L, Müller W, et al. T cell-derived IL-10 determines leishmaniasis disease outcome and is suppressed by a dendritic cell based vaccine. PLoS Pathog (2013) 9(6):e1003476. doi:10.1371/ journal.ppat.1003476

17. Ahuja SS, Reddick RL, Sato N, Montalbo E, Kostecki V, Zhao W, et al. Dendritic cell (DC)based anti-infective strategies: DCs engineered to secrete IL-12 are a potent vaccine in a murine model of an intracellular infection. J Immunol (1999) 163:3890-7.

18. Remer KA, Apetrei C, Schwarz T, Linden C, Moll $H$. Vaccination with plasmacytoid dendritic cells induces protection against infection with Leishmania major in mice. Eur J Immunol (2007) 37(9):2463-73. doi:10.1002/eji.200636780

19. Ghosh M, Pal C, Ray M, Maitra S, Mandal L, Bandyopadhyay S. Dendritic cell based immunotherapy combined with antimony-based chemotherapy cures established murine visceral leishmaniasis. J Immunol (2003) 170(11):5625-9. doi:10. 4049/jimmunol.170.11.5625
20. Schnitzer JK, Berzel S, Fajardo-Moser M, Remer KA, Moll H. Fragments of antigen-loaded dendritic cells (DC) and DC-derived exosomes induce protective immunity against Leishmania major. Vaccine (2010) 28(36):5785-93. doi:10.1016/j. vaccine.2010.06.077

21. Tsagozis P, Karagouni E, Dotsika E. Dendritic cells pulsed with peptides of gp63 induce differential protection against experimental cutaneous leishmaniasis. Int J Immunopathol Pharmacol (2004) 17(3):343-52.

22. Flower DR, Macdonald IK, Ramakrishnan K, Davies MN, Doytchinova IA. Computer aided selection of candidate vaccine antigens. Immunome Res (2010) 3(6 Suppl 2):S1. doi:10.1186/1745-7580-6-S2-S1

23. Patronov A, Doytchinova I. T-cell epitope vaccine design by immunoinformatics. Open Biol (2013) 8(3):120139. doi:10.1098/rsob.120139

24. Agallou M, Athanasiou E, Koutsoni O, Dotsika E, Karagouni E. Experimental validation of multiepitope peptides including promising MHC class I- and II-restricted epitopes of four known Leishmania infantum proteins. Front Immunol (2014) 5:268. doi:10.3389/fimmu.2014.00268

25. Agallou M, Margaroni M, Karagouni E. Cellular vaccination with bone marrow-derived dendritic cells pulsed with a peptide of Leishmania infantum KMP-11 and CpG oligonucleotides induces protection in a murine model of visceral leishmaniasis. Vaccine (2011) 29(31):5053-64. doi:10.1016/j. vaccine.2011.04.089

26. Agallou M, Smirlis D, Soteriadou KP, Karagouni E. Vaccination with Leishmania histone H1pulsed dendritic cells confers protection in murine visceral leishmaniasis. Vaccine (2012) 30(34):5086-93. doi:10.1016/j.vaccine.2012.05. 075

27. Kopf M, Brombacher F, Kohler G, Kienzle G, Widmann KH. IL-4-deficient BALB/c mice resist infection with Leishmania major. J Exp Med (1996) 184:1127-36. doi:10.1084/jem.184.3. 1127

28. Biedermann T, Zimmermann S, Himmelrich H, Gumy A, Egeter O. IL-4 instructs Th1 responses and resistance to Leishmania major in susceptible BALB/c mice. Nat Immunol (2001) 2:1054-60. doi:10.1038/ni725

29. Stäger S, Joshi T, Bankoti R. Immune evasive mechanisms contributing to persistent Leishmania donovani infection. Immunol Res (2010) 47:14-24. doi:10.1007/s12026-009-8135-4

30. Ansari NA, Kumar R, Gautam S, Nylén S, Singh OP. IL-27 and IL-21 are associated with $\mathrm{T}$ cell IL-10 responses in human visceral leishmaniasis. J Immunol (2011) 186:3977-85. doi:10.4049/ jimmunol.1003588

31. Kane MM, Mosser DM. The role of IL-10 in promoting disease progression in leishmaniasis. J Immunol (2001) 166:1141-7. doi:10.4049/ jimmunol.166.2.1141

32. Majumder S, Bhattacharjee S, Paul Chowdhury B, Majumdar S. CXCL10 is critical for the generation of protective CD8 $\mathrm{T}$ cell response induced by antigen pulsed CpG-ODN activated dendritic cells. PLoS One (2012) 7(11):e48727. doi:10.1371/ journal.pone.0048727 
33. Chu RS, Targoni OS, Krieg AM, Lehmann PV, Harding CV. CpG oligodeoxynucleotides act as adjuvants that switch on $\mathrm{T}$ helper 1 (Th1) immunity. J Exp Med (1997) 186:1623-31. doi:10. 1084/jem.186.10.1623

34. Warren TL, Bhatia SK, Acosta AM, Dahle CE, Ratliff TL. APC stimulated by CpG oligodeoxynucleotide enhance activation of MHC class Irestricted T cells. J Immunol (2000) 165:6244-51. doi:10.4049/jimmunol.165.11.6244

35. Gupta G, Bhattacharjee S, Bhattacharyya S, Bhattacharya P, Adhikari A, Mukherjee A. CXC chemokine-mediated protection against visceral leishmaniasis: involvement of the proinflammatory response. J Infect Dis (2009) 200:1300-10. doi:10.1086/605895

36. Gupta G, Majumdar S, Adhikari A, Bhattacharya P, Mukherjee AK, Majumdar SB. Treatment with IP-10 induces host-protective immune response by regulating the $\mathrm{T}$ regulatory cell functioning in Leishmania donovani-infected mice. Med Microbiol Immunol (2011) 200:241-53. doi:10.1007/ s00430-011-0197-y

37. Bonifaz LC, Bonnyay DP, Charalambous A, Darguste DI, Fujii S. In vivo targeting of antigens to maturing dendritic cells via the DEC205 receptor improves $\mathrm{T}$ cell vaccination. J Exp Med (2004) 199:815-24. doi:10.1084/jem. 20032220
38. Trumpfheller C, Longhi MP, Caskey M, Idoyaga J, Bozzacco L. Dendritic cell-targeted protein vaccines: a novel approach to induce T-cell immunity. J Intern Med (2012) 271:183-92. doi:10.1111/ j.1365-2796.2011.02496.x

39. Do Y, Didierlaurent AM, Ryu S, Koh H, Park CG. Induction of pulmonary mucosal immune responses with a protein vaccine targeted to the DEC-205/CD205 receptor. Vaccine (2012) 30:6359-67. doi:10.1016/j.vaccine.2012.08.051

40. Matos I, Mizenina O, Lubkin A, Steinman RM, Idoyaga J. Targeting Leishmania major antigens to dendritic cells in vivo induces protective immunity. PLoS One (2013) 8(6):e67453. doi:10.1371/annotation/5149bf8e-3843-4865a726-0ca2820ee8f8

41. Okwor I, Mou Z, Liu D, Uzonna J. Protective immunity and vaccination against cutaneous leishmaniasis. Front Immunol (2012) 3:128. doi:10. 3389/fimmu.2012.00128

42. Das S, Freier A, Boussoffara T, Das S, Oswald D, Losch FO, et al. Modular multiantigen $\mathrm{T}$ cell epitope-enriched DNA vaccine against human leishmaniasis. Sci Transl Med (2014) 6(234):234ra56. doi:10.1126/scitranslmed. 3008222

43. Tu H, Burke TM, Oderup C, Huang K, Wong $\mathrm{K}$, Lewén $\mathrm{S}$, et al. Robust expansion of dendritic cells in vivo by hydrodynamic FLT3L-FC gene transfer. J Immunol Methods (2014) 413:69-73. doi:10.1016/j.jim.2014.07.008

Conflict of Interest Statement: The authors declare that the research was conducted in the absence of any commercial or financial relationships that could be construed as a potential conflict of interest.

Received: 17 August 2014; paper pending published: 29 October 2014; accepted: 10 November 2014; published online: 26 November 2014.

Citation: Freitas-Silva $R$, Brelaz-de-Castro MCA, Rezende AM and Pereira VR (2014) Targeting dendritic cells as a good alternative to combat Leishmania spp. Front. Immunol. 5:604. doi: 10.3389/fimmu.2014.00604 This article was submitted to Immunotherapies and Vaccines, a section of the journal Frontiers in Immunology. Copyright (C) 2014 Freitas-Silva, Brelaz-de-Castro, Rezende and Pereira. This is an open-access article distributed under the terms of the Creative Commons Attribution License (CC BY). The use, distribution or reproduction in other forums is permitted, provided the original author(s) or licensor are credited and that the original publication in this journal is cited, in accordance with accepted academic practice. No use, distribution or reproduction is permitted which does not comply with these terms. 